\title{
Vapour spies to reveal climate clues
}

Scientists will begin collecting the first nearreal-time measurements of the isotopes in water vapour on Hawaii's Mauna Loa this week, trialling what could prove to be a new way to study climate and weather systems.

The month-long experiment will deploy a trio of laser-based instruments to measure the isotopic composition of water vapour at least once every few minutes. That information can then be used to create a kind of 'life history' of the vapour, whether the source is a nearby forest, evaporation from the ocean or a cold air mass descending from higher in the atmosphere.

"This could be a new way of detecting fundamental changes in Earth's atmospheric circulation," says Joe Galewsky, an atmospheric scientist at the University of New Mexico in Albuquerque.

He says that Mauna Loa was the obvious place to conduct the experiment because of its sheer elevation and its location in the subtropics, which is influenced by both tropical and northerly atmospheric currents. These same attributes made the volcano an ideal place for the atmospheric carbon-dioxide counts recorded by the late Charles David Keeling, a long-time affilliate of the Scripps Institution of Oceanography in San Diego, California.

At almost 3,400 metres above sea level, the main observatory on Mauna Loa is comfortably above the fray of surface air currents. Galewsky and his team conducted a trial-run on nearby
Mauna Kea using flask samples in 2006 and found that the air currents seem to be governed by large-scale atmospheric processes rather than local weather trends (J. Galewsky et al. Geophys. Res. Lett. doi:10.1029/2007GL031330; 2007).

The research ultimately relies on minute differences in the way the isotopologues of water are affected by variables such as evaporation, transpiration and condensation. Heavy water (in which the molecule has an extra neutron) precipitates out of the atmosphere faster than the more common 'light' water isotopologue, and light water evaporates faster.

Scientists commonly study isotopic ratios in things such as ice cores and ocean sediments, but extracting them from water vapour in the air is more difficult. The advent of lasers that can be tuned to the specific absorption frequencies of individual isotopes made this work easier, as did the fact that such devices are now portable.

The team plans to test three such devices simultaneously: one from NASA's Jet Propulsion Laboratory in Pasadena and two commercially available devices that use slightly different technologies. The team will also gather air samples for comparison back in the lab. "We really have to convince ourselves that this works," says David Noone, a climatologist of the University of Colorado at Boulder, who is working on the project.

The next - and for many the most important - step is tying these measurements back to

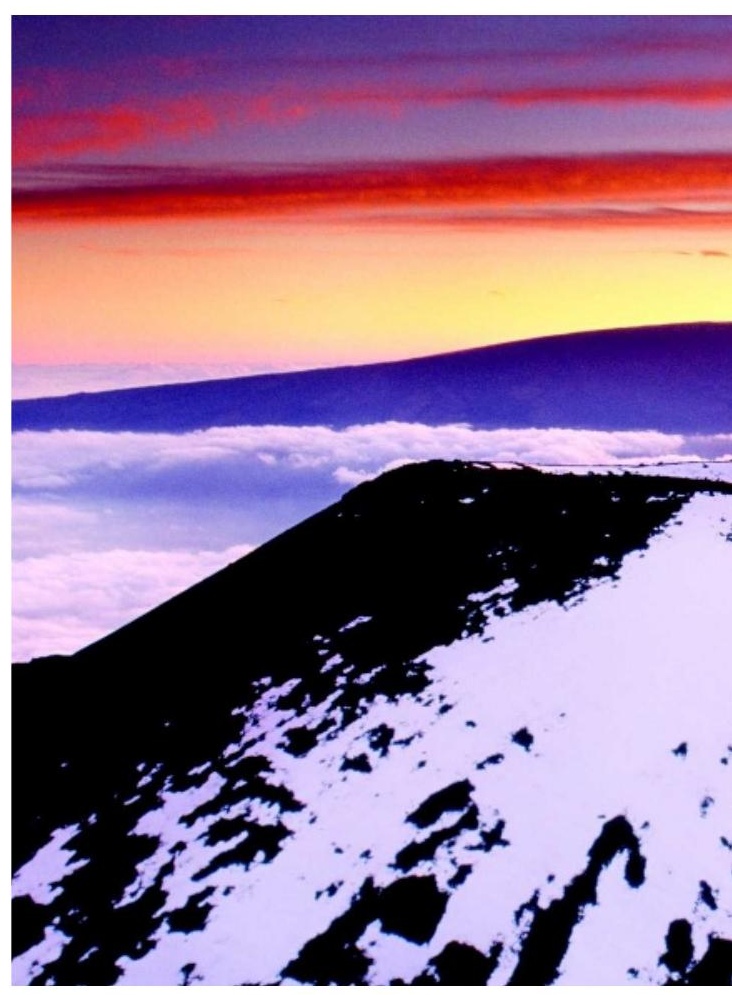

Streams of vapour above Mauna Loa, Hawaii.

satellite data. A comparison of this sort was first published last year by Noone and colleagues in Nature (J. Worden et al. Nature 445, 528532; 2007). In that study, the team analysed water-vapour isotopes using measurements from a passive emissions sensor aboard NASA's Aura satellite, one of two that will be collecting data during the current project.

"This is brand new. This is something that really revolutionizes the study of water vapour," says Gavin Schmidt, a climate modeller at the

\section{Slime and fleas feature in Ig Nobel awards}

Slime moulds exhibit the kind of "contemplative behaviour" that Hamlet is famous for, muses Toshiyuki Nakagaki of Hokkaido University in Japan. “Hamlet couldn't decide what to do so he did nothing. Then he chose a strong course of action." Similarly, slime moulds stop moving when they encounter a toxic substance. "But once action occurs, it too is strong," Nakagaki says.

The slime mould's puzzle-solving ability - Shakespearean or otherwise - is a discovery that is unlikely to change the world, but it won Nakagaki and his colleagues an Ig Nobel Prize for cognitive science last week at the annual event held at Harvard University in Cambridge, Massachusetts. Their research, published in
Nature (T. Nakagaki, H. Yamada \& Á. Tóth Nature $407,470 ; 2000)$, showed that slime moulds looking for food have "the ability to find the minimum-length solution between two points in a labyrinth".

Subsequently, the team has found that moulds can find the shortest path between $30-50$ points, which is something even supercomputers cannot yet work out. "We can't even check the mould's solution," notes Nakagaki, "but it looks good."

From the cognitive feats of slime mould to the physical prowess of fleas: Marie-Christine Cadiergues of the National Veterinary School in Toulouse, France, and her colleagues won the biology Ig Nobel Prize for showing that dog fleas can jump 2 centimetres higher and 10 centimetres farther than cat fleas. "In the daily life of a vet, it's a good thing to know," Cadiergues says.

Other recipients of this year's prizes for amusing research included psychologists Charles Spence of the University of Oxford, UK, and Massimiliano Zampini of the University of Trento in Italy, who won the Nutrition Ig Nobel for research involving eating Pringles potato chips (crisps). 
